\begin{tabular}{ccc}
\hline Bentham OPEN & The Open Urology \& Nephrology \\
JoursMark & Content list available at: www.benthamopen.com/TOUNJ/ & DOI: $10.2174 / 1874303 X 01609010035$ \\
\hline
\end{tabular}

\title{
Treatment of Male Urinary Incontinence with An Adjustable Implantable Medical Device: Ustrap
}

\author{
Pierre Dubernard ${ }^{*}$ and Elie Pricaz \\ Jean Mermoz Private Hospital Urology Department, Lyon, France
}

\begin{abstract}
:
Introduction and Objectives:

Our aim is to develop a device which is simpler, less expensive, but equally or more effective than currently available devices including the artificial urinary sphincter.
\end{abstract}

\section{Method:}

Based on our knowledge of and experience with other devices we designed the Ustrap. The theoretical advantages of our approach are described as is the development to the current $\left(3^{\text {rd }}\right)$ version.

\section{Results:}

For version \#1, implanted in 6 patients, the 5 year follow up includes 2 improved, 2 unchanged, 2 required AUS. For version \#2 implanted in 4 patients, 2 year follow up shows 3 improved, 1 failure.

\section{Conclusions:}

The Ustrap has unique features which distinguish it from current devices. A proposed multicenter prospective clinical trial of version \#3 is awaiting approval.

Keywords: Adjustable male sling, artificial urinary sphincter, male urinary incontinence, polypropylene coating, perisymphyseal straps, radical prostatectomy.

\section{INTRODUCTION}

Urinary incontinence has many causes and adversely impacts the quality of life for a significant proportion of the population. In France according to the 1995 ANDEM (National Agency for Medical Development and Evaluation) report 3 million people were incontinent, of which $30 \%$ were men. Currently, it is estimated that 10 percent of men aged 60 and 30 percent of men aged 90 are incontinent [1].

The overall cost to France in 2011 for urinary incontinence was 3.5 billion Euros. The cost to an incontinent individual can range from 500 to 2500 euros a year.

\section{INDICATIONS}

The Ustrap is primarily intended for use with post-operative male urinary incontinence after prostate surgery. Prostate cancer (71,000 new cases in France in 2012) results in almost 30,000 radical prostatectomies each year [2], 70 to 100,000 in Europe and 90 to 160,000 in the USA. This totals to 180 to 280,000 prostatectomies per year in the Western world. Each year, approximately 980,000 open prostatectomies or endoscopic resections, also potential sources

\footnotetext{
* Address correspondence to these authors at Jean Mermoz Private Hospital Urology Department, Lyon, France; E-mail: pierre.dubernard@wanadoo.fr
} 
of incontinence, are performed for benign prostate hypertrophy.

The rate of incontinence lasting more than one year after a radical prostatectomy is 3 to $15 \%$, of which 3 to $5 \%$ is severe and 5 to $15 \%$ is average to light.

In France, approximately 1,400 IMDs, including 1,200 artificial urinary sphincters (AUS) and 400 various other devices (tapes or balloons) are implanted each year. This estimate is considerably underestimated taking into account the limitation of the indications related to the complexity and cost of AUSs and the uncertain effectiveness of the majority of tapes.

The actual global usage is approximately 15 to 30,000 IMDs per year.

\section{REVIEW OF EXISTING DEVICES: [3 - 5]}

\section{- Artificial Urinary Sphincter (AUS):}

It is the "gold standard" of the available implantable devices (75 to $90 \%$ success rate) [6, 7]. It reproduces the natural sphincter function, but it is expensive, and requires invasive surgery by an experienced surgeon. Despite several decades of development it is a complex mechanism which is subject to multiple complications (infection, erosion and urethral atrophy). This leads to corrective surgery in more than 55\% of cases during an average lifetime of 10 years. The AUS requires the patient to be able to manipulate it several times daily for each urination.

\section{- Adjustable Micro-Balloons:}

(Pro-Act) placed in a sub-cervical and latero-urethral position $[8,9]$ have a success rate of 35 to $75 \%$, with 12 to $58 \%$ experiencing complications (bladder or urethral perforation migration) which require removal in $30 \%$ of cases.

\section{- Non-Adjustable:}

Tapes with 2, or more recently 4 arms, are simple and inexpensive but have varying efficiency and are sources of strangulation as a result of a tying effect on the urethra. They apply a lateral or oblique tension, which is less effective than vertical tension. Once implanted they are no longer adjustable.

- Invance (AMS) is a polypropylene sheet stretched between the ischiopubic rami [10, 11] with fixation via bone screws. This device has been discontinued due to lack of effectiveness and various complications (pain and osteitis).

- Advance (AMS) is a sling placed at the bulbomembranous urethra [12], the aim of which is to reposition the sphincter support structures.

- I-Stops Toms (CL Médical) [13], Surgimesh M-sling (Aspide Médical) or Virtue (Coloplast) [14] are placed post-bulbar and have at least 2 arms passed laterally across the transobturator foramen.

\section{- Adjustable Devices:}

There are three main adjustable devices:

○ Remeex from Neomedic [15] is a polypropylene sub-urethral sling connected to a supra-pubic regulator by a mono filament wire passed retropubically.

- Argus from Promedon [16] consists of a sub-urethral silicone foam pad directly in contact with the urethra and connected to the adjustment rings via retropubic or transobturator notched pipes. These two devices require another operation for each adjustment.

- The latest device "Phorbas" is similar to the device from AMI.

- Atoms from A.M.I. [17] consists of a sub-urethral silicone pad directly in contact with the urethra, adjustable via an implantable inguinal port. The lateral transobturator orientation arm bypasses the ischiopubic rami in order to return to attach to the back part of the prosthesis. 


\section{DESIGN OBJECTIVES FOR THE USTRAP (HSUPS):}

There were three objectives which led to the design of this device:

- A large longitudinal contact surface following the shape of the urethra like a genuine hammock.

- Upward vertical tension provided by both retro and presymphyseal straps connected above the pubis.

- Adjustable pressure via an inflatable pad coated in polypropylene and connected to a readjustment port by means of a catheter.

\section{DESCRIPTION OF THE USTRAP (HSUPS): (Fig. 1).}

- Polypropylene prosthesis.

- Double trapezoidal "teabag" sheet (50/45-40 mm.)

- Four arms (straps).

2 posterior: retro-pubic.

2 anterior: pre-pubic (one with catheter).

- Silicon pad within the polypropylene bag, connected via the catheter to the suprapubic port for adjusting the pressure in the sub-urethral pad.

Fig. (1). Ustrap.

\section{How It Works: (Fig. 2)}

- Trapezoid-shaped longitudinal pre and post-bulbar support.

- Equal distribution of the pressure provided by a large urethral contact surface.

- Upward vertical suspension through 4 arms: perisymphyseal straps (patent 2007).

- Inflatable pad in the shape of a bellows: adjustable pressure (implantable chamber). 


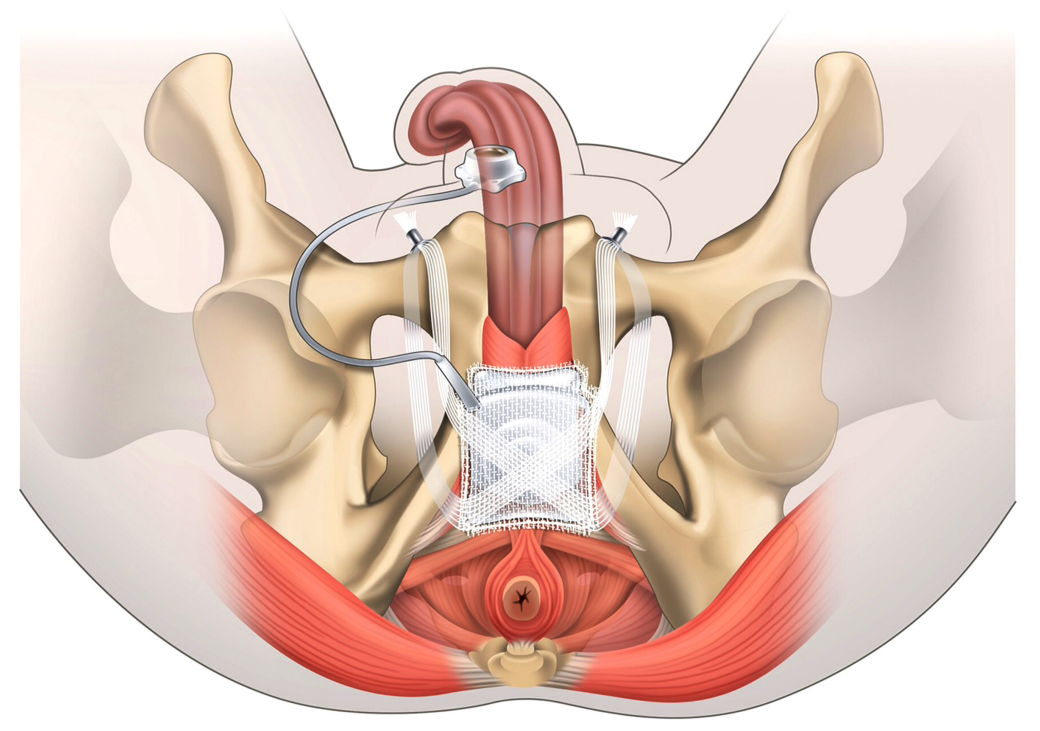

Fig. (2). Anatomical positioning diagram.

\section{Technical Benefits: (Fig. 3)}

The surgical procedure, utilizing a suitable tunnelling device, is simple and quick (small incisions and limited dissection). The tunneling device facilitates the passage of the straps thanks to the mounted security sheaths. The sheaths are micro perforated, to easily identify any bladder injury. .

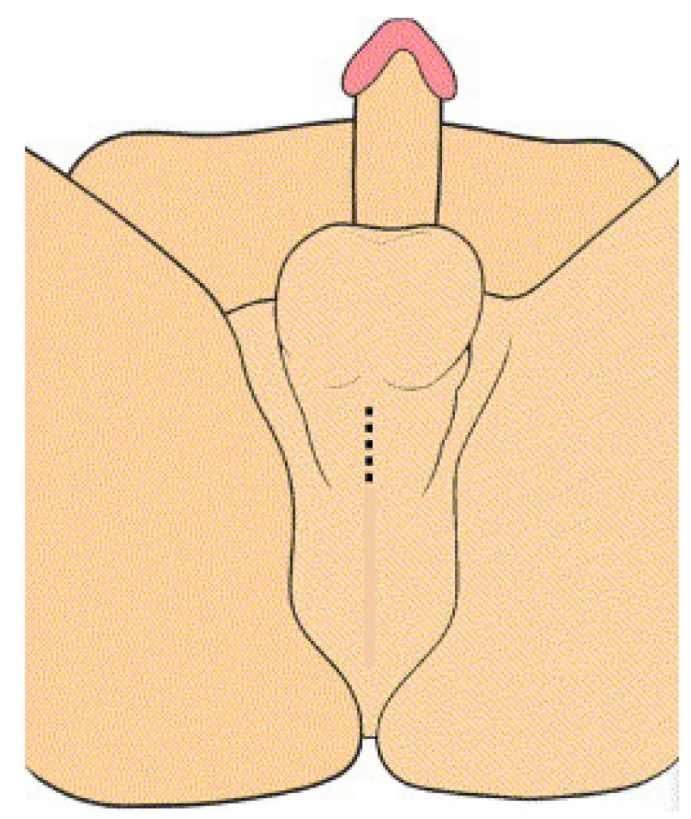

Fig. (3). Incisions.

\section{COMPARATIVE BENEFITS}

- These is no transversal strangulation (tying effect) thanks to the large longitudinal sub-urethral contact surface.

- The support applies maximally effective upward pressure(neither lateral nor oblique) while following and adjusting to the shape of the urethrocavernous body.

- The perisymphyseal straps which arch over the pubic bone do not require bone anchoring.

- There is no dissection of the urethra (no cuff so no risk of erosion, ischemia or atrophy of the urethra). 
- The silicone is not in direct contact with the urethra.

- The pressure is adjustable on demand with no manipulation by the patient.

- The pressure can be adjusted according to the various degrees of incontinence [1 - 3].

- It is reproducible and reversible (an artificial sphincter can be implanted in case of failure).

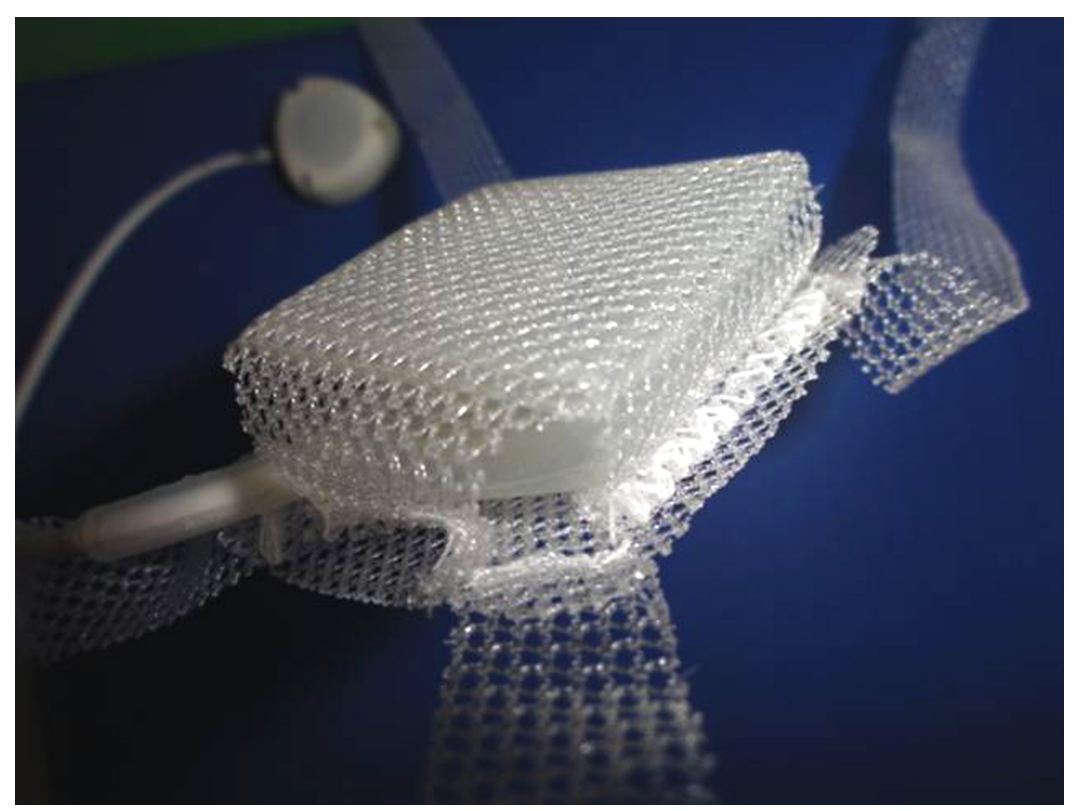

Fig. (4). Version 1 (quadrangular windows and flat straps).

\section{CONCEPTUAL EVOLUTION OF THE DEVICE: 3 PHASES}

The first version Fig. (4) had quadrangular windows in order to allow the silicone pad to be extended dorsally and had flat straps to encourage good suprapubic support.

However, hernias due to protrusion of the silicone pad through the windows led to failure of the device, as well as excess elasticity and lack of resistance of the straps.

The second version Fig. (5) consisted of a pad in the shape of a bellows coated with polypropylene, thus replacing the windows at the edges and increasing the capacity for vertically guided expansion. The straps were made tubular in order to strengthen them and reduce their elasticity, but this caused difficulties for suprapubic fixation.

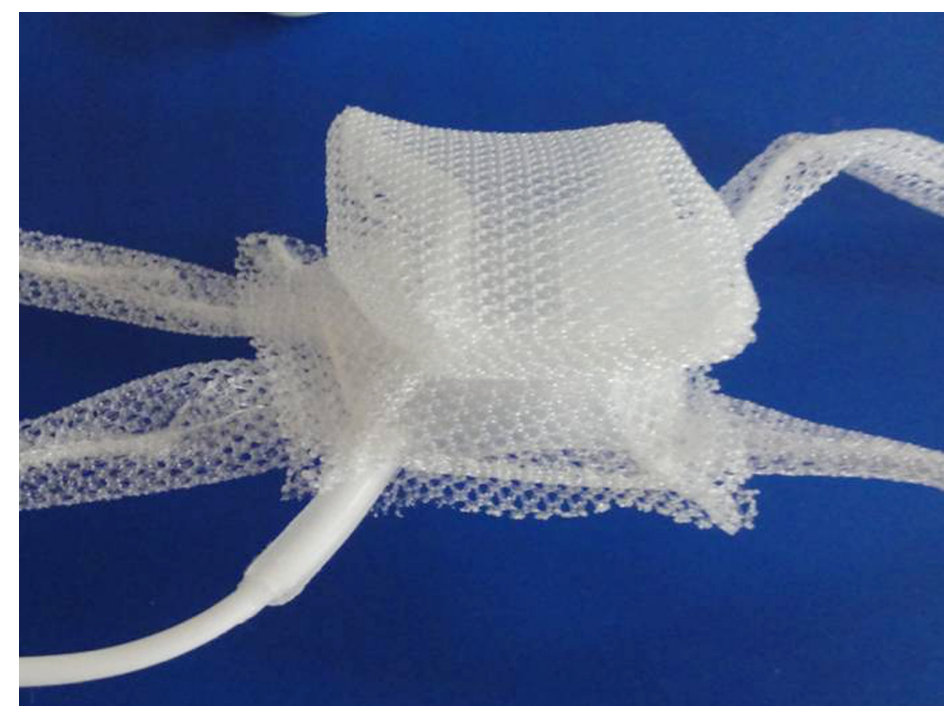

Fig. (5). Version 2 (bellows-shaped hammock and tubular straps). 


\section{THE CURRENT VERSION (FIG. 6A AND FIG. 6B) INCORPORATES VARIOUS IMPROVEMENTS:}

- The hammock, positioned under the bulbourethral muscle, is comprised of a silicone pad in the shape of a bellows packaged in a polypropylene coating.

- It is suspended from the quadrangular straps adjusted under the ventral sheet also made from polypropylene mono filament, which has no elasticity.

- The end of the straps are tapered, sheathed and crimped by repairable coloured threads which have an autotightening buckle for fixing to the ancillary device.

- The tunnelling device allows the straps to be passed perisymphyseally, behind and in front of the pubic symphysis.

- The simple crimping system, made of titanium, firmly attaches the two ipsilateral straps supported on the pubis on each side.

- The implantable port, made from polyoxymethylene filled with barium sulphate which includes a silicone elastomer septum, is connected to the implantable port via a catheter.

- The catheter, also made from silicone elastomer, runs the length of the right-hand presymphyseal strap.

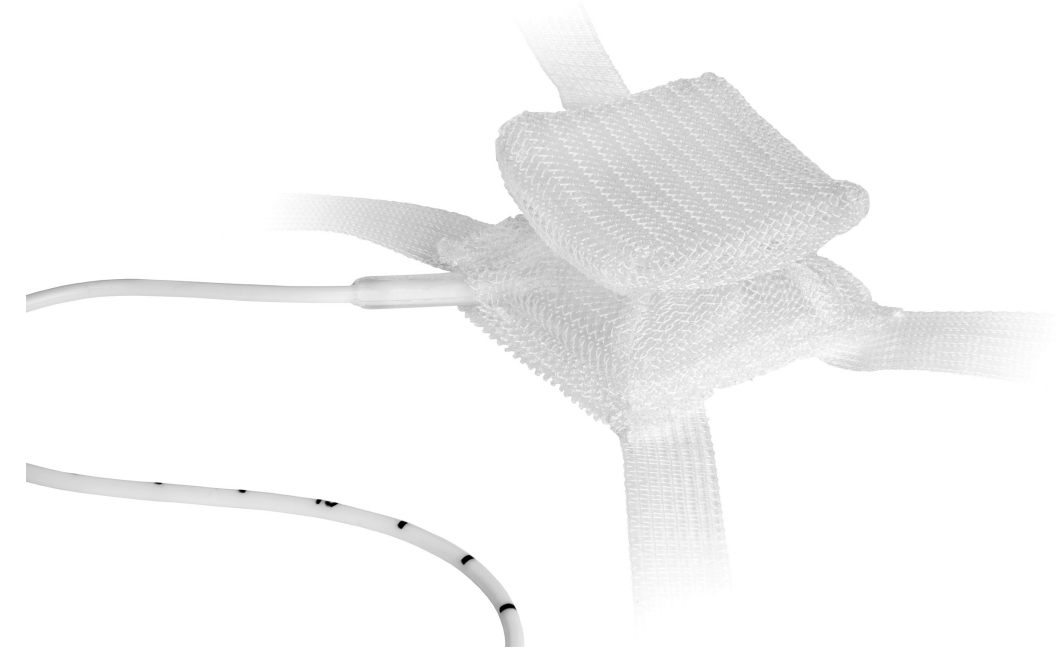

Fig. (6a). Version 3 current anterior (dorsal) and posterior (ventral) faces.

\section{RESULTS OF THE PRELIMINARY FEASIBILITY STUDIES}

\section{First Version:}

After having obtained approval from the ANSM [National Agency for the Safety of Medicines and Medical Devices], 6 initial patients received the first version of the implant at our centre (HPJM) (from 09/03 to 17/05/2010).

We did not observe any serious complications or worsening of the initial level of incontinence.

After one year: 2 complete failures, 3 complete successes (improvement of better than 95\%) and 1 partial success (improvement of 75\%)

Long term: Occurrence of a sudden failure of the IMD in a patient after 18 months following a major physical exercise.

After current follow-up period of 5 years: 2 patients improved together ( 1 complete, 1 partial), 2 status quo and 2 patients who required uncomplicated implantation of an artificial urinary sphincter (AUS).

The failures were analysed and attributed to insufficient urethral outflow resistance and excess elasticity in the straps. This was secondary to the type of knitting of the polypropylene, as well as to "herniation" of the silicone pad through the openings made at the edges in order to facilitate the expansion of the latter. 


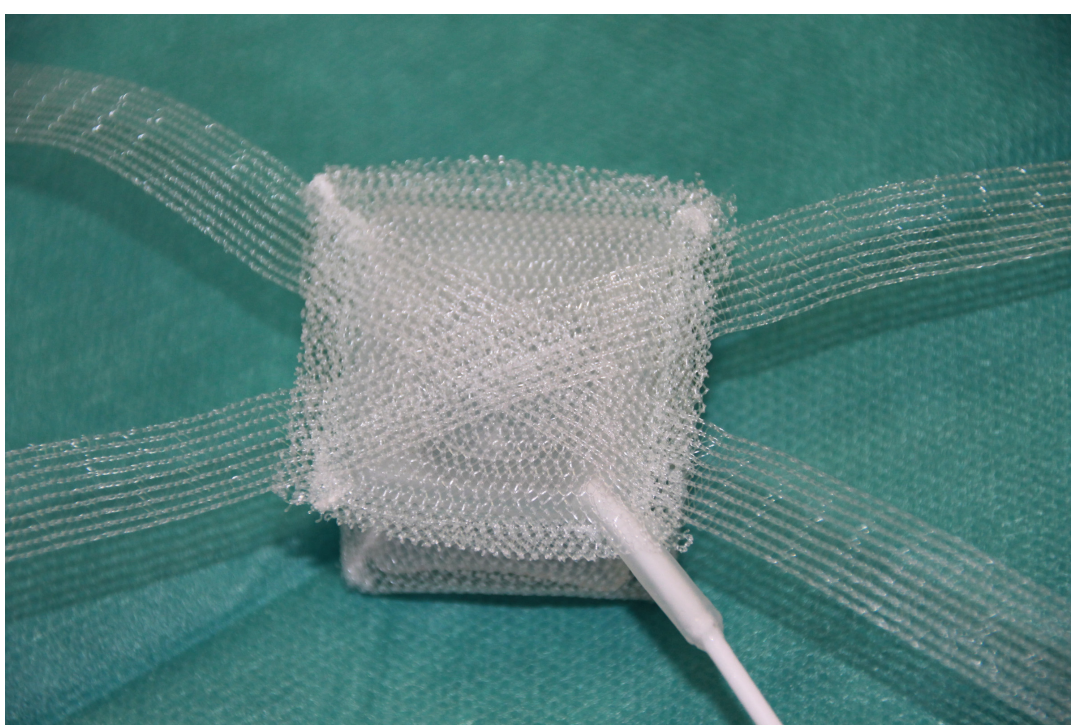

Fig. (6b). Version 3 current anterior (dorsal) and posterior (ventral) faces.

\section{Second Version}

The device was modified to be in the shape of a bellows coated in polypropylene. This allows for more ample upward expansion. The straps were made tubular in order to make them less elastic. This last modification presented a problem for suprapubic fixation owing to obstruction of the straps hindering their attachment and the absence of a suitable system for blocking them.

Despite this technical issue, in the 4 patients implanted with this second version, (from 06/12/2011 to 17/05/2012 we observed $75 \%$ good results after a period of 2 years: 3 successes (improvement estimated by the patients as better than 90\%) and 1 failure, fixable with an AUS. The study was the interrupted by our decision to change the company manufacturing the device.

\section{Third Version}

The current version, manufactured by a new company, is the result of improvements to the two prior versions and will be the subject of a multi-centre clinical trial once CE marking has been obtained.

\section{Implantation Protocol}

\section{Position And Preparation Of The Patient}

- The operation can be performed under spinal or general anaesthesia.

- The patient is placed in a supine position, legs slightly apart.

- Rectal enema with Betadine.

- The genital region is cleaned with an iodised polyvidine solution for 10 minutes or according to the procedure approved by the hospital.

- The sterile fields are placed excluding the anal region.

- A CH.18 indwelling catheter is inserted and left indwelling.

\section{Surgical Approach}

- A short transversal perinal incision or at the penoscrotal junction exposes the bulbocavernosus muscle and the median sagittal ligament which is dissected.

- The index marks the lower edge of the ischiopubic rami in order to initiate passage with the foam tip of the curved scissors along the transverse ligament of the pelvis.

- Two suprapubic incisions, $2 \mathrm{~cm}$ to the left and $3 \mathrm{~cm}$ to the right, are made on either side of the median line up to the sheath of the rectus abdominus. This is incised with the tip of the scissors underneath the posterior face of the pubic symphysis 


\section{Placement of The Ustrap:}

\section{Posterior Phase:}

The first micro-perforated sheath is inserted on the ancillary tool by the non-tapered side. The ancillary tool is moved upwards under the lower edge of the ischio-pubic branch flush with the posterior surface of the pubis, using its curve, to meet the right suprapubic incision. The ancillary tool is then removed but the sheath remains in place. The same operation is performed on the adelphe side to position the second sheath.

A cystoscopy is then performed to check the integrity of the bladder. The tunneling device is moved down through both sheaths. The 2 posterior straps can then be drawn up and the hammock can be placed in a proper position against the ventral face of the bulbourethral muscle.

2. Anterior Phase:

Remove the right and left safety sheaths. The ancillary device, introduced through the same suprapubic incision, is passed from the top down, in front of the pubis, to enter the latero-urethral space. It grasps the anterior strap, draws it up and externalises it at the same level as the posterior strap.

The catheter is passed along the same route as the right anterior strap before being connected to the implantable chamber.

\section{Positioning And Adjustment Of The Ustrap:}

The hammock is placed on the bulbospongiosus muscle by pulling simultaneously, equally and symmetrically, on the posterior and anterior straps. Vigorous force must be applied.

The right posterior and anterior straps are inserted into one of the fixation elements. The crimping tool is positioned on the end of the fixation element. It is advanced through the suprapubic incision until contact is made with the pubis. Once the element has been advanced and is in position, pressure is applied to the tool in order to crimp the fixation element onto the straps. We recommend proceeding with care in order to prevent the risk of tearing the straps through successive stretching and to maintain the tension balance in the system. It is important that the pad remains well centered. The straps should have equal tension to avoid displacement of the device.

The stiffener is positioned on the catheter, then the implantable port is connected to the catheter. The stiffener is then placed and connected to the port. The port is placed in a medial space established by means of the righthand suprapubic incision where the catheter has been externalised.

The port is fixed at several points in order to prevent it from flipping.

A test of the hammock inflation in place is carried out using a solution of physiologic saline $(\mathrm{NaCl} 0.9 \%)$ added to an equal amount of contrast agent. One can leave the hammock completely empty or instill as little as $2 \mathrm{ml}$. The initial volume, like the secondary adjustment volume, is left to the discretion of the surgeon ( maximum filling volume: $20 \mathrm{ml}$ ).

We recommend noting the inflation volume which will serve as a reference for subsequent adjustments.

\section{CONCLUSION}

In this article, we review current anti-incontinence devices, document the development and pilot studies of the first 2 versions of the Ustrap. We report the modifications incorporated into the $3^{\text {rd }}$ version, which will be subjected to a multicentre clinical trial.

\section{CONFLICT OF INTEREST}

The authors confirm that this article content has no conflict of interest.

\section{ACKNOWLEDGEMENTS}

The authors wish to thank Richard J Macchia, MD for assistance in the preparation of the English translation of this article. 


\section{REFERENCES}

[1] AFU(Association Française d'Urologie). Fiche d'information 08/03/2011.

[2] Haab Fr. Rapport sur le thème de l'incontinence urinaire. Avril 2007, Rapport au Ministère de la santé et des solidarités April 2007.

[3] Bauer RM, Bastian PJ, Gozzi C, Stief CG. Postprostatectomy incontinence: all about diagnosis and management. Eur Urol 2009; 55(2): 322-33. [http://dx.doi.org/10.1016/j.eururo.2008.10.029] [PMID: 18963418]

[4] Grise P, Caremel R. Male stress urinary incontinence: the place of alternatives to an artificial urinary sphincter. Prog Urol 2009; 19(12): $897-901$.

[http://dx.doi.org/10.1016/j.purol.2009.09.030] [PMID: 19963188]

[5] Caremel R, Corcos J. Incontinence after radical prostatectomy: Anything new in its management? Can Urol Assoc J 2014; 8(5-6): 202-12. [http://dx.doi.org/10.5489/cuaj.1349] [PMID: 25024791]

[6] Rocha TF, Gomes CM, Mitre AI, Arap S, Srougi M. A prospective study evaluating the efficacy of the artificial sphincter AMS 800 for the treatment of postradical prostatectomy urinary incontinence and the correlation between preoperative urodynamic and surgical outcomes. Urology 2008; 71(1): 85-9. [http://dx.doi.org/10.1016/j.urology.2007.09.009] [PMID: 18242371]

[7] Wilson S, Delk J II, Henry GD, Siegel AL. New surgical technique for sphincter urinary control system using upper transverse scrotal incision. J Urol 2003; 169(1): 261-4.

[http://dx.doi.org/10.1016/S0022-5347(05)64082-7] [PMID: 12478150]

[8] Hübner WA, Schlarp OM. Treatment of incontinence after prostatectomy using a new minimally invasive device: adjustable continence therapy. BJU Int 2005; 96(4): 587-94. [http://dx.doi.org/10.1111/j.1464-410X.2005.05689.x] [PMID: 16104915]

[9] Lebret T, Cour F, Benchetrit J, et al. Treatment of postprostatectomy stress urinary incontinence using a minimally invasive adjustable continence balloon device, ProACT: results of a preliminary, multicenter, pilot study. Urology 2008; 71(2): 256-60. [http://dx.doi.org/10.1016/j.urology.2007.08.062] [PMID: 18308096]

[10] Fassi-Fehri H, Badet L, Cherass A, et al. Efficacy of the InVance male sling in men with stress urinary incontinence. Eur Urol 2007; 51(2): 498-503.

[http://dx.doi.org/10.1016/j.eururo.2006.08.042] [PMID: 16996679]

[11] Giberti C, Gallo F, Schenone M, Cortese P. The bone-anchor sub-urethral sling for the treatment of iatrogenic male incontinence: subjective and objective assessment after 41 months of mean follow-up. World J Urol 2008; 26(2): 173-8. [http://dx.doi.org/10.1007/s00345-007-0222-3] [PMID: 17982750]

[12] Gozzi C, Becker AJ, Bauer R, Bastian PJ. Early results of transobturator sling suspension for male urinary incontinence following radical prostatectomy. Eur Urol 2008; 54(4): 960-1. [http://dx.doi.org/10.1016/j.eururo.2008.04.096] [PMID: 18468777]

[13] Grise P, Vautherin R, Njinou-Ngninkeu B, Bochereau G, Lienhart J, Saussine C. I-STOP TOMS transobturator male sling, a minimally invasive treatment for post-prostatectomy incontinence: continence improvement and tolerability. Urology 2012; 79(2): 458-63. [http://dx.doi.org/10.1016/j.urology.2011.08.078] [PMID: 22188755]

[14] Comiter CV, Nitti V, Elliot C, Rhee E. A new quadratic sling for male stress incontinence: retrograde leak point pressure as a measure of urethral resistance. J Urol 2012; 187(2): 563-8. [http://dx.doi.org/10.1016/j.juro.2011.09.152] [PMID: 22177174]

[15] Sousa-Escandón A, 1Cabrera J, Mantovani F, et al. Adjustable suburethral sling (male remeex system) in the treatment of male stress urinary incontinence: amulticentric European study. Eur Urol 2007; 52(5): 1473-9. [http://dx.doi.org/10.1016/j.eururo.2007.05.017] [PMID: 17560016]

[16] Romano SV, Metrebian SE, Vaz F, et al. An adjustable male sling for treating urinary incontinence after prostatectomy: a phase III multicentre trial. BJU Int 2006; 97(3): 533-9. [http://dx.doi.org/10.1111/j.1464-410X.2006.06002.x] [PMID: 16469021]

[17] Hoda MR, Primus G, Fischereder K, et al. Early results of a European multicentre experience with a new self-anchoring adjustable transobturator system for treatment of stress urinary incontinence in men. BJU Int 2013; 111(2): 296-303. [http://dx.doi.org/10.1111/j.1464-410X.2012.11482.x] [PMID: 23186285]

Received: May 11, 2015 Revised: September 1, 2015 Accepted: August 25, 2015

(C) Dubernard \& Pricaz; Licensee Bentham Open

This is an open access article licensed under the terms of the Creative Commons Attribution-Non-Commercial 4.0 International Public License (CC BY-NC 4.0) (https://creativecommons.org/licenses/by-nc/4.0/legalcode), which permits unrestricted, non-commercial use, distribution and reproduction in any medium, provided the work is properly cited. 